\title{
NON-OPERATIVE MANAGEMENT OF PERFORATED GASTRODUODENAL ULCER- A PROSPECTIVE OBSERVATIONAL STUDY IN A RURAL TERTIARY CARE HOSPITAL
}

\author{
Dipan Mukhopadhyay', Partha Sarathi Dutta²
}

${ }_{1}^{1}$ Assistant Professor, Department of General Surgery, Calcutta National Medical College, Kolkata.

${ }^{2}$ Assistant Professor, Department of General Surgery, Calcutta National Medical College, Kolkata.

\begin{tabular}{l}
\hline ABSTRACT \\
Perforation remains a major life-threatening complication of peptic ulcer disease. Morbidity and mortality following perforated \\
peptic ulcer remains substantial.
\end{tabular}

\section{MATERIALS AND METHODS}

A prospective study of the outcome of non-operative treatment of patients of perforated peptic ulcer was conducted for a period of 2009 to 2014. Patients with clinical and radiological diagnosis of perforated peptic ulcer were included for conservative management consisting of intravenous fluid, nasogastric suction, antibiotics and proton pump inhibitor (Omeprazole).

\section{RESULTS}

Four (04) of these 26 patients did not improve after 12 hours of conservative management and required an operation. There is no mortality in this conservative management group and morbidity is $4 \%$. Median hospital stay was 10 days.

\section{CONCLUSION}

The non-operative management of perforated peptic ulcer in the era of proton pump inhibitor may be possible in selected patients, provided strict guidelines are followed.

\section{KEYWORDS}

Gastroduodenal Ulcer, Perforation, Peptic Ulcer Disease, Non-Operative Management, Proton Pump Inhibitor.

HOW TO CITE THIS ARTICLE: Mukhopadhyay D, Dutta PS. Non-operative management of perforated gastroduodenal ulcer- a prospective observational study in a rural tertiary care hospital. J. Evolution Med. Dent. Sci. 2018;7(05):650-652, DOI: $10.14260 /$ jemds/2018/147

\section{BACKGROUND}

Peptic ulcer disease is one of the most prevalent diseases of gastrointestinal tract. It has two wide spectrums, one is gastric ulcer and the other is duodenal ulcer and Helicobacter pylori infection association is seen in $75 \%$ - 90\% cases.[1] The common complication of peptic ulcer disease is bleeding, perforation and obstruction. Graham's patch repair of perforated peptic ulcer is a standard therapeutic option employed in most surgical units.[2,3] In 1946, Taylor successfully managed 27 cases of perforated peptic ulcer with 1 mortality with intravenous fluids, nasogastric suction and serial abdominal examination. ${ }^{44,5]}$ Before that Crisp described adhesion formation process in 1843 following peptic ulcer perforation. While the conservative treatment of perforative gastroduodenal ulcer was proposed by Wangensteen in 1935.[6] Berne and Rosoff in 1950 describe that a surgeon is able to know spontaneous seal of perforation by performing a gastroduodenogram using a water soluble contrast media.[7] On the other hand conservative management was opted in some patients not eligible for surgical repair, because of severe co-morbidities with haemodynamic stability and no sign of frank sepsis despite surgical delay.

'Financial or Other Competing Interest': None.

Submission 22-12-2017, Peer Review 15-01-2018,

Acceptance 22-01-2018, Published 29-01-2018.

Corresponding Author:

Dr. Partha Sarathi Dutta

Department of General Surgery,

Calcutta National Medical College,

Kolkata.

E-mail: drpsd11@gmail.com

DOI: $10.14260 /$ jemds $/ 2018 / 147$

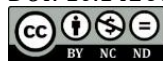

The aim of this study is to access its efficacy and longterm outcome.

\section{MATERIALS AND METHODS}

This prospective case study was performed in the Department of Surgery, BS Medical College, Bankura, India from January 2009 to January 2014. The total number of cases included in this study was 26 [Table 1]. All the cases were diagnosed by history, clinical examination, routine haematological investigations, serum electrolytes, x-ray of abdomen in erect and supine posture and ultrasonography of abdomen followed by Gastrografin contrast study.

Inclusion criteria of this study consists of diagnosis of peptic ulcer (clinical and radiological), haemodynamic stability and age between 20 to 70 years. ${ }^{[4,8]}$

Conservative management consists of intravenous fluid, intravenous antibiotics (ceftriaxone/piperacillin-tazobactam, metronidazole), IV Omeprazole $40 \mathrm{mg}$ twice daily, nasogastric suction by Ryle's tube (no. 18 for male, no. 16 for female). The patient was monitored hourly. Pulse, blood pressure, temperature and urine output and 12 hourly chart for intake/ output. Emergency surgeon evaluated the patient every 6 hourly and conservative management was abandoned if the patient failed to improve or deteriorated, i.e. increased intensity of abdominal pain, developed tachycardia, pyrexia and abdominal distention after 12 hourly of conservative management. Clear fluid allowed after 5 days of conservative management after clamping of Ryle's tube. The patient was closely watched for any sign of peritonitis and if the patient tolerated well then liquid diet was allowed and nasogastric tube was removed. The patient had been discharged after 2 weeks with anti-ulcer treatment for one 
month after discharge and upper GI endoscopy, rapid urease test after 1 month and received anti HP treatment. Those are tested positive for $\mathrm{H}$. pylori.

\section{RESULTS}

During the study period (2009 - 2014), the patient with a diagnosis of peptic ulcer was allocated to conservative management who meets the inclusion criteria. The clinical characteristic of the selected 26 cases are shown is Table 1 and Table 2.

\begin{tabular}{|c|c|}
\hline Features/ Characteristics & No. of Patients (N- 26) \\
\hline Male & 25 \\
Female & 1 \\
Mean age in years & $45(20-70)$ \\
Smoker/ Tobacco use & 20 \\
Alcoholic & 16 \\
NSAID & 11 \\
Steroid & 2 \\
H/O Dyspepsia & 19 \\
\hline Associated Co-morbidity & No. of Patients (N- 26) \\
\hline Heart Disease & 5 \\
Diabetes Mellitus & 7 \\
Chronic Obstructive & 6 \\
Pulmonary Disease & 1 \\
Cirrhosis & 7 \\
No Co-morbidity & 2 \\
\hline ASA Fitness Grade & No. of Patients (N- 26) \\
\hline I & 8 \\
II & 7 \\
III & 2 \\
IV & 2 \\
V & Table 1. Demography and Clinical Data \\
\hline
\end{tabular}

\begin{tabular}{|c|c|}
\hline Duration in Hours (Range) & No. of Patients (N- 26) \\
\hline$<4$ & 2 \\
$4-8$ & 6 \\
$8-12$ & 8 \\
$12-24$ & 5 \\
$24-48$ & 5 \\
\hline \multicolumn{2}{|c|}{ Table 2. Duration of Perforation at Admission } \\
\hline
\end{tabular}

22 of the 26 cases responded well to the conservative non-operative treatment, while remaining 4 cases failed to improve after 12 hours of observation and they underwent emergency laparotomy. Hence, the success rate of conservative management is $85 \%$. One patient withdraws from the study after 8 hours and also undergone emergency surgery. There was no significant difference between the failure group and successful group with regards to age duration of perforation, medication or length of ulcer symptoms and hospital stay. Four patients (04) who underwent laparotomy after 12 hours of trial had unsealed perforation and were true failure of conservative treatment.

\begin{tabular}{|c|c|c|}
\hline Features & $\begin{array}{c}\text { Failed } \\
\text { Conservative } \\
\text { Treatment (N= 4) }\end{array}$ & $\begin{array}{c}\text { Successful } \\
\text { Conservative } \\
\text { Treatment (N= 22) }\end{array}$ \\
\hline Mean age (years) & 44 & 46 \\
\hline $\begin{array}{c}\text { Mean duration of } \\
\text { perforation(hours) }\end{array}$ & 6 & 12 \\
\hline Mean hospital stay & 12 & 10 \\
\hline Complication & 2 & 6 \\
\hline \multicolumn{2}{|c|}{ Table 3. Comparison between Failed Group } \\
and Successful Group
\end{tabular}

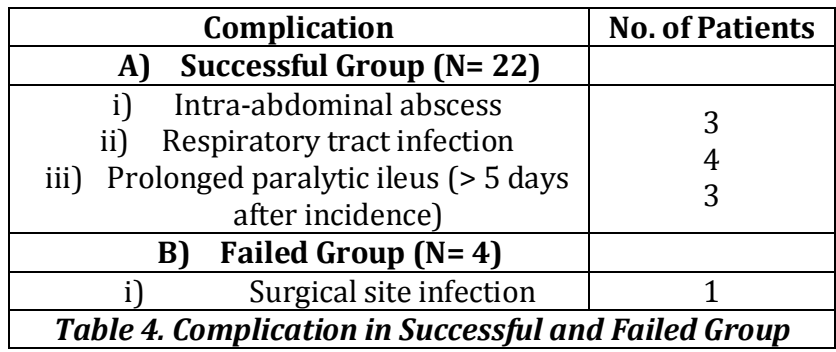

\section{Follow-Up}

The twenty cases were followed for 1 year and six (06) cases did not turn-up for follow-up. All cases received anti-ulcer therapy for one month and were advised upper GI endoscopy and rapid urease test after one month. Anti H. pylori treatment was given for 14 days who were tested positive for H. pylori.

\section{DISCUSSION}

The common treatment for patient with perforated peptic ulcer is surgical repair.[9] In most cases, Graham's omental patch repair is commonly performed followed by $\mathrm{H} 2$ receptor antagonist or proton pump inhibitor, anti-HP eradication therapy is initiated for the patient found having $\mathrm{H}$. pylori infection. H. pylori infection reported $80 \%$ cases of perforated duodenal ulcer. $H$. pylori infection resulted in favour of perforation than haemorrhage or obstruction.

In our study, we analysed the safety and efficacy of conservative management (known as Taylor method) ${ }^{[10]}$ of perforated gastroduodenal ulcer. Surgical closure of the peroration has remained the standard therapy until now. Recently conservative management has drawn much attention. Conservative management of perforated gastroduodenal ulcer has not had a wide acceptance as an alternative approach to surgery. The first half of $20^{\text {th }}$ century[11,12] has shown that after perforation, self-sealing occurs in high frequency by formation of fibrin clot quickly on and around the perforation. This is the start of definite closure, which associates adhesion between perforation and adjacent organ and healing of gastrointestinal tract. This phenomenon of self-healing is efficient in at least $50 \%$ of the patients.[13] Indeed, it is a common experience for surgeons who operate for perforated ulcer to observe that they first have to mobilise the perforation from adjacent organs before able to suture it.[14] Songne et al opine that presence of septic shock at the time of admission is a critical determinant whether the patient will respond to non-operative management.

\section{The Basis behind Conservative Management}

- In gastroduodenal perforation the peritoneal cavity usually remains sterile for 12 hours, because the bacterial load is low in upper gastrointestinal tract.[14]

- Peritonitis is no longer now considered the killer as it is used to be, because with the aid of the new armamentarium at our disposal the peritoneum will localise usually and absorb the contaminant.

- Concern over the peritoneal soilage had led the surgeons to believe that it is the prime importance to wash out the peritoneal cavity carefully with a large volume of normal saline at the time of operation.[15] Rosoff reported that out of 109 patients treated non-operatively during the acute phase, only 3 developed intra-abdominal 
abscess.[15] Re-leakage has occurred in 2 of 109 patients who were treated non-operatively as reported by Berne and Rosoff.[16]

\section{Issue of Co-Morbidity}

Conservative management was developed at the time when surgical closure was associated with risk factors including age more than seventy years, use of steroidal and nonsteroidal anti-inflammatory drugs and concomitant medical illness and presence of shock (SBP < $100 \mathrm{mmHg}$ ). [17]

One of the major issues with the conservative management is risk of misdiagnosis. However, regular reassessment clinically and radiologically (repeat if necessary) by an experienced surgeon, the conservative treatment can be discontinued. The criteria for spontaneous sealing are uniform filling of gastroduodenogram, demonstration of ulcer and lack of spillage. Absence of filling of gastroduodenogram in spite of lack of spillage is not acceptable.[18] Failure of conservative management can be predicted by the size of pneumoperitoneum/ size of L1 vertebrae if greater than one and presence of shock at admission. According to Taylor's guidelines and previous reports, the presence of haemodynamic instability even in a moribund patent favours urgent laparotomy.[19] Therefore, careful stratification according to inclusion criteria is the key point for successful outcome of non-operative management and also to avoid delayed surgical closure of perforation. ${ }^{[20]}$

\section{CONCLUSION}

Conservative treatment of perforated peptic ulcer in the era of advanced antibiotics and proton pump inhibitor is an alternative therapeutic option if strict inclusion criteria and guidelines are followed. However, the presence of shock at admission is still associated with high mortality and should encourage early surgical intervention in these moribund patients.

\section{REFERENCES}

[1] Gisbert J, Legido J, Garcia-Sanz I, et al. Helicobacter pylori and perforated peptic ulcer: prevalence of the infection and role of non-steroidal anti-inflammatory drugs. Dig Liver Dis 2004;36(2):116-20.

[2] Lau H. Laparoscopic repair of perforated peptic ulcer: a meta-analysis. Surg Endosc 2004;18(7):1013-21.

[3] Siu WT, Chau CH, Law BK, et al. Routine use of laparoscopic repair for perforated peptic ulcer. $\mathrm{Br}$ J Surg 2004;91(4):481-4.
[4] Taylor H. Perforated peptic ulcer: treated without operation. Lancet 1946;2(6422):441-4.

[5] Taylor H, Warren RP. Perforated acute and chronic peptic ulcer: conservative treatment. Lancet 1956;270(6920):397-9.

[6] Wangensteen 0 . Non-operative treatment of localized perforations of the duodenum. Minn Med 1935; 18:477.

[7] Berne CJ. Management of perforated peptic ulcer. Surgery 1958;44:591-603.

[8] Crofts TJ, Park KG, Steele RJ, et al. A randomized trial of non-operative treatment for perforated peptic ulcer. N Engl J Med 1989;320(15):970-3.

[9] Bertram HF. Non-operative treatment of perforated duodenal ulcer. Preliminary report of 16 consecutive cases with no mortality. Annals of Surgery 1950;132(6):1075-85.

[10] Menegaux F. Taylor method: antiquity or reality. Ann Chir 2004;129(10):561-2.

[11] Taylor $\mathrm{H}$. The non-surgical treatment of perforated peptic ulcer. Gastroenterology 1957;33:353-68.

[12] Staed JR. Conservative treatment of perforated peptic ulcer. Lancet 1951;257(6645):12-7.

[13] Donovan AJ, Vinson TC, Maulsby GO, et al. Selective treatment of duodenal ulcer with perforation. Ann Surg 1979;189(5):627-36.

[14] Bucher P, Oulhaci W, Morel P, et al. Results of conservative treatment for perforated gastroduodenal ulcers in patients not eligible for surgical repair. Swiss Med Wkly 2007;137(23-24):337-40.

[15] Nusree R. Conservative management of perforated peptic ulcer. The THAI Journal of Surgery 2005;26:5-8.

[16] Berne CJ, Rosoff L. Acute perforation of peptic ulcer. In: Nyhus LN, Wastell O. eds. Surgery of the stomach and duodenum. Boston, Mass: Little Brown \& Co Inc., 1986:457-73.

[17] Irvin TT. Mortality and perforated peptic ulcer: case for risk stratification in elderly patients. Br J Surg 1989;76(3):215-8.

[18] Berne TV, Donovan AJ. Non-operative treatment of perforated duodenal ulcer. Arch Surg 1989;124(7):830-2.

[19] Ball AB, Thomas PA, Evans SJ. Operative mortality after perforated peptic ulcer. $\mathrm{Br}$ J Surg 1989;76(5):521-2.

[20] Marshall C, Ramaswamy P, Bergin FG, et al. Evaluation of a protocol for the non-operative management of perforated peptic ulcer. Br J Surg 1999;86(1):131-4. 